|Araştırma Makalesi / Research Article |

\title{
Türkiye’de Müzik Eğitimi Ana Bilim Dallarında Görev Yapan Öğretim Elemanlarının Alan İçi Çalışmalarına Genel Bir Bakış ${ }^{1}$
}

\section{An Overview of the Field Studies of Teaching Staff at Music Education Departments in Turkey}

\section{Barış Kardeş², Gökalp Parasız ${ }^{3}$}

Anahtar Kelimeler
akademisyen
bilimsel yayın
müzik eğitimi

\section{Keywords}

academician

scientific publication

music education

Başvuru Tarihi/Received

30.05.2019

Kabul Tarihi /Accepted

07.10.2019

\section{Öz}

Bu çalışmada Türkiye' de müzik eğitimi alanında, öğretim elemanlarının yapmış olduğu akademik çalışmalar incelenmiştir. Tarih boyunca müzik eğitimi ile ilgili pek çok araştırma yapılmış, müzik eğitiminin tanımı, sınırları ve etkilendiği alanlar farklıık göstermiştir. Bu bağlamda müzik eğitimi alanında yapılan çalışmaların araştırma konuları, çalışma alanları ve kullanılan yöntemler zaman içinde değişiklik göstermiştir. Bu nedenle ülkemizde yapılan müzik eğitimi alanındaki akademik çalışmaların incelenmesi alanda bulunduğumuz yeri ve alandaki araștırma eğilimlerini belirlememizde önemli bilgiler sağlayacaktır. Çalışmanın amacı müzik eğitimi alanında yapılan akademik çalışmaların konularını inceleyerek bir durum değerlendirmesi yapmaktır. Bu araştırma sonucunda, müzik eğitimi anabilim dallarında görev yapan 230 öğretim elemanının akademik çalışmalarına ulaşıımış, bu çalışmaların araştırma konuları, akademisyenlerin çaldıkları çalgılar incelenmiş ve sınıflandırılmışır. Bu araştırma, doktora ve sanatta yeterlik derecesine sahip öğretim elemanları ve yayımlamış oldukları tüm bilimsel çalışmaları ile sınırlı tutulmuştur. 2018 yılı itibariyle YÖK Akademik veri tabanında ve üniversitelerin web sayfalarında yapılan incelemeler sonucu Türkiye'de müzik eğitimi alanında 30 lisans programı bulunmaktadır. Çalışmada elde edilen veriler istatistiksel olarak analiz edilmiştir. Yapılan incelemeler sonucunda Türkiye'de müzik eğitimi anabilim dallarında yapılan akademik çalışmalarının tamamının 4681 adet olduğu saptanmıştır. Bu çalışmalar incelendiğinde uluslararası yayınların daha fazla olduğu, yönetilen tezlerin büyük çoğunluğunun yüksek lisans tezi olduğu, demografik yapı incelendiğinde akademisyenlerin enstrümanlarının bağlama, flüt, gitar, kanun, keman, klarnet, kontrbas, piyano, ut, viyola, viyolonsel yanı sıra ses eğitimi (şan) şeklinde dağılım gösterdiği tespit edilmiştir. Bu dağııımda, bireysel çalgısı piyano olan öğretim elemanlarının sayııının diğer çalgılara göre daha fazla olduğu belirlenmiştir.

\section{Abstract}

In this study, the academic studies of the teaching staff in Turkey are examined in the field of music education. Throughout history, many studies on music education have been done, the definition of music education, boundaries and the areas affected have varied. In this context, research subjects, study areas and methods used in the field of music education have changed over time. Therefore, examining the academic studies in the field of music education in our country will provide important information in determining the location and research trends in the field. The aim of the study is to make a case study by examining the subjects of academic studies in the field of music education. As a result of the research, the academic studies of 230 instructors working in the departments of music education were reached and the research topics of these studies and the instruments played by the academicians were examined and classified. This research is limited to all the scientific studies published by the faculty members who have the degree of doctorate and proficiency in art. As of the 2018 Higher Education Academic database and the results of research conducted at the university web page, there are 30 undergraduate programs in music education in Turkey. The data obtained in the study were analyzed statistically. As a result of the examinations, it was found that the academic studies conducted in the departments of music education were 4681 in Turkey. When these studies are examined, it is determined that there are more international publications and the majority of the theses administered are master thesis. When the demographic structure is examined, it is determined that the instruments of the academicians are distributed in the form of tying, flute, guitar, law, violin, clarinet, contrabass, piano, ut, viola, cello as well as voice training (singing). In this distribution, it was determined that the number of faculty members whose individual instrument was piano was more than the other instruments.

\footnotetext{
1 Uluslararası Necatibey Eğitim ve Sosyal Bilimler Araştırmaları Kongresi'nde (2018) özet bildiri olarak sunulmuştur.

${ }^{2}$ Balıkesir Üniversitesi, Necatibey Eğitim Fakültesi, Güzel Sanatlar Eğitimi Bölümü, Balıkesir, TÜRKiYE; https://orcid.org/0000-0002-4802-5202

${ }^{3}$ Balıkesir Üniversitesi, Necatibey Eğitim Fakültesi, Güzel Sanatlar Eğitimi Bölümü, Balıkesir, TÜRKiYE; https://orcid.org/0000-0002-9349-0293
} 


\section{Extended Abstract}

\section{Introduction}

Human beings use the information they investigate, observe and experience with the curiosity of learning by nature and need to transfer this information to the next generation.

In Turkey, a large part of the music teacher needs, the university faculties of education are covered by the education department of fine arts department of music education. In addition to this, undergraduate students of music faculties of conservatory and fine arts faculties can take courses related to teaching profession and teach music in formal education institutions affiliated with Ministry of National Education.

During the undergraduate education, students who are directed to graduate education with the studies that will improve the researcher aspect of the students begin to take the first steps towards becoming academicians and scientists of the future with the knowledge and experience in the stages they pass. Music education departments of the faculties of education also contribute to the field of science with postgraduate education programs.

Throughout history, many studies on music education have been done, the definition of music education, boundaries and areas affected have varied. In this context, research subjects, study areas and methods used in the field of music education have changed over time. Thus, the study of academic studies in music education conducted in Turkey, determine research trends in our area where we are in the area and will provide important data.

\section{Method}

The screening model was used to determine the current situation related to the subject of the study. Screening models are research approaches that aim to describe a situation that exists in the past or the present. The subject, subject, or object, which is the subject of the research, is tried to be defined as it is and within its own conditions. They do not attempt to change them in any way (Karasar, 2011, p. 77).

Sönmez and Alacapınar (2014) described the screening model as a way of describing the living, present and present ones by describing and explaining what happened. The work or event observed in the screening method does not interfere and does not try to be controlled. It is evaluated in its own conditions (p. 47)

In order to obtain the preliminary information necessary for the research, the related web pages accessed by the researchers from the official sites of the universities and the relevant information about the academicians were carefully studied on the https://akademik.yok.gov.tr/AkademikArama/ database web site, which was provided by YÖK.

The data obtained by the researchers were examined and the necessary classifications were made; Descriptive statistics such as frequency distribution and percentage were used to describe. Descriptive statistics help the researcher to reduce, summarize, and make meaningful with a large number of data and information (Semerci et al., 2015, p. 59).

In the research, in the stage of classifying the academic activities according to the subjects, expert opinions were consulted. Unclassified topics are named as 'other'.

The research is limited to only scientific articles, books, papers, dissertations, project studies and awards and patents with the academic staff who are proficient in doctorate and arts and working actively in 2018-December.

\section{Result and Discussion}

In this study, the academic studies of the teaching staff in Turkey are examined in the field of music education. In this study, music education in Turkey when working in the department doctorate / art proficiency have made the teaching staff, were examined for their work inside the area. According to this, it is determined that the number of faculty members working in 30 music education departments and having PhD degree is 230 with the data obtained from the academic database of YÖK and the websites of the relevant universities. All of academic studies in the department of music education in Turkey is determined to be 4681 pieces.

Music education degree program, Turkey's all partners in all university programs are carried out as in faculties of education. In this program, both educational and scientific courses are given as well as educational and supporting activities that support scientific research in most of the other field courses. Upon successful completion of the undergraduate education, students are entitled to receive the title of "scientist" and, doctor of science "with postgraduate programs. It can be said that the number of postgraduate programs for music education is less than the number of graduate programs in other fields and it is increasing. With this increase, it is expected and desired that the number and quality of graduate students will increase. However, this situation is very closely related to undergraduate education. Çetinkaya (2006) stated that science and education should act together; He emphasized the necessity of constructing creative and questioning minds starting from pre-school stage, developing researcher thinking, adding scientific method to daily life and it can be provided with healthy education policies.

With the development of healthy education policies, the products of research, which will be carried out with scientific research methods and techniques, will sit on a solid ground and will have a firm place in the literature, no matter which field of science. For this purpose, the importance of education, science and scientific research is emphasized in acquiring the most basic achievements and analyzing and interpreting more complex structures. 
It is very important to gain the technical competencies and scientific attitudes and behaviors in the upbringing of the scientists to be trained with graduate education (master and doctorate). If enough research training cannot be given to the scientists to be trained, both the researches will be full of mistakes and the time, labor and money spent on research will be wasted (Erdem, 2012, p. 166).

In the light of all these, scientific studies in the field of music education should be integrated into music and music education activities in the world, to be able to detect the problems in the field accurately and in place, to know and evaluate the literature well, to be able to use the correct and on-site scientific methods with unbiased and realistic approaches. contribution to music education research is expected. 
GíRiş

İnsan, doğası gereği öğrenme merakı ile araştırdığı, gözlemlediği ve tecrübe ettiği bilgileri kullanır ve bu bilgileri kendinden sonraki nesillere de aktarma gereği duyar.

Erkuş (2017), insanın en önemli özelliklerinden birinin, ortaya çıkardığı her türlü bilgiyi gelecek kuşaklara aktarabilmesi ve bu birikimlilik özelliği ile her doğan insan yavrusunun, atalarının geçtiği aşamalardan geçmek zorunda kalmadığını, ateşi, tekerleği, elektriği yeni baştan bulmak çabasına girişmediğini belirtmekte, ortaya çıkan her yeni bilginin, eski bilgilerin üzerine yapılandığını ve bilimsel ilerlemenin de temel yapı taşlarından birini oluşturduğunu söylemektedir (s. 29). "Tüm canlılarda olduğu gibi insan da araştırmacı olarak doğar; fakat yanlış kültürleme sonucu bu araştırmacı yeteneği körleştirilir. Bu bağlamda, insanın doğuştan getirdiği araştırma yeteneği her dönemde geliştirilmeli ve eğitim buna göre düzenlenmelidir" (Sönmez ve Alacapınar, 2016, s. 4).

"Eğitim, bireyi temel alan ve bireyin gelişim sürecindeki gerekli bilgi, beceri ve davranışları doğru biçimde kazanmasını sağlayarak, bireyi hayata hazırlamayı amaçlayan en temel yapıdır. Bu temel yapının doğru işleyebilmesi, sürekli gelişen ve değişim gösteren küresel yapı içerisindeki yenilikleri yakından takip ederek kültürel olgularla beraber planlı ve programlı bir şekilde sürdürülerek sağlanabilir" (Parasız, 2009, s. 1).

Yaşar (1998), bilim ve eğitimin, bir bütünün ayrılmaz iki parçası olduğunu ve bu iki öğe arasında çift yönlü bir etkileşim olduğunu belirtmekte, bilim ve eğitimden yararlanmanın hem bireyin hem toplumun en doğal hakkı olduğunu, hem de çağdaşlığın bir ölçütü olarak kabul edildiğini ifade etmektedir. Ayrıca, ülkedeki insan gücü kaynaklarının geliştirilmesi doğrultusunda çaba gösterilmesi gerektiğini ve bu amaçla, eğitime gereken önem verilerek eğitimin bilimsel temelde ele alınmasıyla bilimsel ve teknolojik bakımdan hedeflere ulaşılabileceğini belirtmektedir (s.181).

"Bilim, Latince "scientica" kelimesinden türetilen, İngilizlerin "science", Almanların "wissenschaft”, Osmanlının "ilim” ve "fen" olarak adlandırdığı bilim, kısaca bilgi edinme, bilgi öğrenimi amaçlı araştırma olarak tanımlanabilir. İngilizce "knowledge" ve Almanca "information" kelimeleri ile ifade edilen bilgi de merak giderici öğrenme, bilgi edinmedir. Genelde doğa, insan ve toplum konularında bilimsel, deneysel veya teorik yöntemlerle elde edilmiş düzenli ve örgütlü bilgidir" (Doğan, 2016, s. 3).

Kaptan (1998) bilimin, davranışları, doğal olay ve olguları ve bunlar arasındaki ilişkileri olduğu gibi göstermeye çalışan betimlemeli bir etkinlik; bunları yorumlayıp anlamlı genellemeler sistemler içinde organize etmeye, nedenlerini belirlemeye yönelen açıklamalı bir çaba ve gelecekte olacakları kestirmeyi ve doğayı kontrol altına almayı amaç edinen yordamlı ve kontrollü bir etkinlik olduğunu belirtmektedir (s. 8).

"Bilim doğada meydana gelen olayların nedenlerini, birbiriyle olan bağlantılarını bulan, onları genelleştiren, kuramsallaştıran ve bu kuramsal bilgi yardımıyla sonradan meydana gelecek olayların nasıl ve ne zaman meydana geleceğini önceden saptayan entelektüel bir uğraştır" (Topdemir ve Unat, 2015, s. 2). "Bilim ya da araştırma, çağdaş bireyin ve toplumların bilgi edinmede, sorunlarını çözmede kullandığı temel yoldur. Bilgi edinmenin bir yolu olarak bilim, bilimsel yöntemi anlatır" (Büyüköztürk ve diğerleri, 2017, s. 4).

Ekiz'e (2015) göre, bilimsel araştırma, sosyal ve fiziksel fenomenalar (olgular) hakkında bilimsel bilgi elde etmek için sistematik, planlı ve bazen de yapay olarak kontrollü yürütülen etkinliklerdir (s.18). Bu etkinlikler sayesinde objektif bilgiler elde edilerek, doğru analizlerle kapsayıc yorumlar yapılabilir.

Erkuş (2017), güvenilir çözümleri hedefleyen; verileri sistemli ve planlı toplayan; toplanan verilerin analizini yapan; bulguları değerlendirerek yorumlayan; sonuç olarak araştırmayı mutlaka rapor eden çalışmaların, bilimin amaçlarına ve ölçütlerine uygun olarak yapılan bilimsel araştırmalar olduğunu belirtmektir (s.69).

"Bilime ilişkin etik sorunlar, bilimin geniş kapsamı içerisinde, ilgili tarafların (uygulayıcı, uygulanan ve etkilenen), yani bilim insanını ve bilimsel sürece katılan ve sonuçlarından etkilenenleri (kişiler ve toplum) kapsayacak şekilde ele alınmalıdır. Bu alan, neredeyse toplumun tüm ilişkilerini kapsayacak genişliktedir. Bu çerçeve, bilim ve etik ilişkisinin çok yönlü ve karmaşık bir sorun yumağı olduğunu gösterir. Her araştırma ve yayın etkinliği (faaliyeti) bilimsel değildir. Bilimsel çalışma, bilimsel kurallar izlenerek gerçekleştirilir" (Ecevit, 2006, s. 81).

Düztepe (2004), bilimsel çalışmalarda, araştırmaların bilimsel temele dayanması ve gerçeğe en yakın sonuçlara ulaşabilmesi için, araştırmacı yaratıcılığının, en önemli etken olarak görüldüğünü belirtmektedir (s.53).

Arıkan, Demir (2009) ve Ortaş (2004)' a göre üniversiteler, çeşitli alanlarda eğitim ve araştırma yapan, gelişmiş bir ekonominin ihtiyacı olan teknik ve yönetsel bilginin üretildiği ve bu bilgiyi üretmek üzere nitelikli bireyler yetiştiren yükseköğrenim ve bilim kurumlarıdır.

Bilgi işçileri olarak nitelendirilen akademisyenler, insan kaynağının daha verimli hale getirilmesinde kritik bir rol üstlenmişler, yaptıkları bilimsel faaliyetler ile bilgi üretme sürecine ve üniversitelerin bilgi üreten merkezler olmalarına katkıda bulunarak ülkelerin kalkınmasında önemli bir rol üstlenmişlerdir. (Özer, 2011; Alparslan, 2014).

“Akademisyenlik kavramı ve bu kavramı besleyen temel dinamiklerle ilgili tartışmaların kavramın kendisi kadar eskiye dayandı̆̆ı bilinmektedir. Buna rağmen tüm toplumsal değişimler ve bu değişimlerle gelen yeni tartışmalar sonucunda akademisyenliğin öğretim yönelimli ve/veya araştırma yönelimli olması ikilemi güncelliğini korumaktadır. Akademisyenlik kavramıyla ilgili bu ikilemi daha iyi anlamak için tarihsel süreç bağlamında yükseköğretimde meydana gelen değişimler ve bu değişimlerin akademisyenlik kavramı üzerindeki etkilerini iyi analiz etmek gerekmektedir" (Odabaşı ve diğerleri, 2010). 
Akademisyenlerin araştırma yapmanın yanı sıra eğitim-öğretim misyonları da vardır. Boyer (1990) bilginin keşfi, entegrasyon, uygulama ve öğretim olmak üzere akademisyenlerin dört eylemi yerine getirdikleri yaklaşımını ortaya koymuştur. Ancak, Deem ve Lucas (2007)' a göre akademisyenlerin çoğu, akademik kariyerlerinde yükselme hedefleri doğrultusunda bilimsel araştırmaya öğretmenlikten daha fazla değer vermektedirler.

"Bilimsel araştırma, keşfetme ve alanyazına katkıda bulunmak için yapılır" (Verburgh ve diğerleri, 2007). Akademisyenlerin bilimsel araştırmalarında, literatürün önemi tartışılmaz bir durumdur. Buradan hareketle, bilginin gizli kalmaması, aktarımı ve bilimsel çalışmaların birbirleriyle olan ilişkisel durumu değerlendirilerek yapılan yorumlamalar, bilimsel araştırmaların daha doğru ve daha kapsamlı bir şekilde alana katkıda bulunmalarını sağlar.

Cumhuriyetin ilanı ile birlikte Türkiye'de, bilimsel araştırma faaliyetlerini desteklemek adına bu alanda atılımlar yapılmış ve çağdaşlaşma yolunda daha hızlı yol almak için pek çok girişimde bulunulmuştur.

Sönmez ve Alacapınar (2016), bu durumu şöyle özetlemektedir;

"Ülkemizde bilimin her alandaki etkileri kendini gösterdi, bilime dayalı kalkınmanın, güvenliğin daha güçlü ve kolay olacağı anlaşıldı. Ayrıca Atatürk'ün "hayatta en hakiki mürşit ilimdir; fendir.” özdeyişinin önemi ortaya çıktı. Böyle olunca ülkemizde bilime ve bilimsel araştırmaya ilgi, gittikçe ve yoğun bir şekilde arttı. TÜBiTAK, Üniversiteler; Milli Savunma Bakanlığı, büyük sanayi ve devlet kuruluşlarının kurduğu ARGE'ler bilimsel araştırma sürecini hızlandırdı, bilim anlayışını olgunlaştırıp değiştirdi. Bilimsel yayınlar ve onların nitelikleri, tartışma konusu olmaya başladı. Bilimde etik, ön plana çıktı. YÖK'te, yayınların etik kurallara uygunluğunu denetleyen bir kurul oluştu. Hakemli dergilerde yayımlananlar, bilimsel özellikler açısından gözden geçirildi ve denetlendi. Üniversitelerin lisans, yüksek lisans ve doktora programlarına Bilimsel Araştırma teknikleri/yöntemleri adlı dersler konuldu ve okutuldu. Bu alanda yazılan kitaplara gereksinim arttı. Yayın sayısında bir patlama oldu. Eğitimde bilimsel araştırma ile öğrenme savunulmaya ve uygulanmaya başlandı".

“2000'li yılların başlarından beri gelişmiş ülkeler, bilgi-tabanlı ekonomi ve bilgi-tabanlı toplum sürecini yaşamaktalar. Bu süreçte bilginin önemi daha da artmış ve bilgi önemli bir üretim metası haline gelmiştir. Teknoloji, küreselleşme ve rekabet dinamikleri yükseköğretim alanını olağanüstü bir şekilde etkilemiş ve bütün ülkeler, daha iyi bilgi üreten sistemler üzerinde olağanüstü çabalar sarf etmektedirler. Yeni stratejiler uygulamaktadırlar. Yükseköğretimdeki okullaşma oranları bütün ülkelerde artmaktadır" (Günay, 2011, s. 120).

Tomakin (2009), öğretim elemanının (örnek Yrd. Doç. Doç. Prof.) kendi alanıyla ilgili lisansüstü çalışmalar yaparak uzmanlaşmış kişiler olduğunu ve kendi alanlarıyla ilgili topluma açıklayıcı, bilgilendirici bilgiler vermesinin, kendi bireysel tecrübelerini toplumla paylaşmasının doğal bir süreç olduğunu belirtmektedir (s.115).

"Yükseköğretim kurumlarının ve bu kurumlarda görev yapan öğretim üyelerinin görevi sadece "meslek insanı yetiştirmek",

"araştırma yapmak" ve "topluma hizmet sunmak" değildir. Aynı zamanda belli bir bilim alanında bilimsel çalışma yapabilecek ve geleceğin öğretim üyesi adayı "bilim insanları" nı "yüksek lisans" ve "doktora" eğitimiyle yetiştirmek yükseköğretim kurumlarının ve bu kurumlarda görev yapan öğretim üyelerinin görevidir" (Erdem, 2012, s. 26).

“Öğretim üyesi hepimizin kabul edeceği gibi; aydınlanmış, geniş bilgili, görgülü, ufku geniş, toplumun gelişme dinamiklerini yaratan, topluma öncülük eden ve o toplumun beyin takımını oluşturan kişidir. Öğretim üyesinin üç temel görevi bulunmaktadır:

1) Eğitim ve öğretim,

2) Bilimsel araştırma,

3) Bulunduğu coğrafyadaki toplumun bilinçlenmesini sağlamak” (Ortaş, 2004, s. 11).

"Öğretim elemanlarının bilimsel çalışma yapma ve yayın yeteneği sonucu ortaya çıkan eserler (kitap, makale, bildiri, tebliğ, proje, sanat dalındaki eserler, burslar, ödüller, yabancı dil ve bilim sınavlarındaki başarılar, editörlükler, atıflar) onun akademik performansını belirtir. Akademik performansı yüksek olan akademisyenler, uygun zemin ve ortam buldukları üniversitelerde verimli ve üretken olurlar" (Okur, 2007, s. 63).

"Cumhuriyetin ilanı ile birlikte her alanda başlayan değişim ve gelişim hareketleri, müzik ve müzik eğitiminde de kendini oldukça belirgin bir şekilde hissettirmiştir. Cumhuriyet dönemi içinde günümüz müzik eğitim anlayışının temelleri atılmış ve bu dönemi izleyen süreçte de atılan temellerin üzerinde yükselinmiştir" (Şahin, 2008, s. 270).

Türkiye'de müzik öğretmeni yetiştirmenin başlangıcından günümüze gerçekleştirilen ana yapılanmalar şöyledir;

- $\quad$ MEB'e bağlı Okul (1924)

- Akademiye bağlı Yüksekokul (1935)

- Yüksekokula bağlı Bölüm (1937)

- Üniversite-Fakülteye bağlı Bölüm (1982)

- Üniversite-Fakülte-Bölüme bağlı Anabilim/Anasanat Dalı (1997)

- Üniversite-Fakülte-Bölüme bağlı Anabilim/Anasanat Dalı́nda Program(1997) (Uçan, 2005, s. 280).

Türkiye'de, müzik öğretmeni ihtiyacının büyük bir kısmını üniversitelerin eğitim fakülteleri güzel sanatlar eğitimi bölümü müzik eğitimi anabilim dalları lisans eğitimi mezunları karşılamaktadır. Bununla birlikte konservatuar ve güzel sanatlar fakültelerinin 
müzik bölümü lisans öğrencileri de öğretmenlik mesleğine yönelik dersleri alarak Milli Eğitim Bakanlığı'na bağlı örgün eğitim kurumlarında müzik öğretmenliği yapabilmektedir.

Lisans eğitimleri sürecinde öğrencilerin araştırmacı yönünü geliştirecek çalışmalarla lisansüstü eğitime de yönlendirilen öğrenciler, geçtikleri aşamalar sürecinde bilgi ve tecrübe sahibi olarak geleceğin akademisyenleri ve bilim insanları olma yolunda ilk adımlarını atmaya başlarlar. Eğitim fakülteleri müzik eğitimi ana bilim dalları, lisans eğitimi sonrasında lisansüstü eğitim programlarıyla bilim alanına da önemli katkılar sağlamaktadır.

Tarih boyunca müzik eğitimi ile ilgili pek çok araştırma yapılmış, müzik eğitiminin tanımı, sınırları ve etkilendiği alanlar farkılık göstermiştir. Bu bağlamda müzik eğitimi alanında yapılan çalışmaların araştırma konuları, çalışma alanları ve kullanılan yöntemler zaman içinde değişiklik göstermiştir.

Araştırmanın amacı; müzik eğitimi alanında görev yapan akademisyenlerin, akademik çalışmalarını nicelik yönünden inceleyerek mevcut durumun tespit edilmesi ve değerlendirilmesidir.

Türkiye'de yapılan müzik eğitimi alanındaki akademik çalışmaların durum tespiti, alanda bulunduğumuz yeri belirlemek, araştırma eğilimlerine ve yapılacak olan çalışmaların planlamalarına katkı sağlamak açısından önem arz etmektedir.

Buradan hareketle, araştırmanın problem cümlesi, "Türkiye'de müzik eğitimi anabilim dallarında aktif olarak görev yapan öğretim elemanlarının, ulusal ve uluslararası akademik çalışmaları ile ilgili mevcut durum nasıldır?” şeklinde belirlenmiştir.

\section{YÖNTEM}

Araştırmada, gerekli verilerin elde edilebilmesi, elde edilen veriler doğrultusunda sınıflandırılması, sayıların ve içeriğin tespit edilebilmesi amacı ile 2018 yılı verileri baz alınarak, üniversitelerin müzik eğitimi ana bilim dallarında aktif olarak görev yapan doktora ve sanatta yeterlik derecesine sahip öğretim elemanlarının bilimsel çalışmalarının tespit edilebilmesi amacı ile tarama modeli kullanılmıştır.

"Tarama modelleri, geçmişte ya da halen var olan bir durumu var olduğu şekliyle betimlemeyi amaçlayan araştırma yaklaşımlarıdır. Araştırmaya konu olan olay, birey ya da nesne, kendi koşulları içinde ve olduğu gibi tanımlanmaya çalışılır. Onları, herhangi bir şekilde değiştirme, etkileme çabası gösterilmez" (Karasar, 2011, s. 77).

Sönmez ve Alacapınar (2014) tarama modelini, “yaşayanların, hali hazırda var olanların, yaşananların ne olduğunun betimlenip açıklanarak ortaya konulması olarak ele alınabilir" şeklinde tanımlamışlardır. Tarama yönteminde gözlenen iş ya da olaya müdahale edilmez ve kontrol altına alınmaya çalışılmaz. Kendi koşulları içinde değerlendirilir (s. 47).

\section{Verilerin Toplanması}

Araştırma için gerekli olan ön bilgilerin edinilmesi amacıyla araştırmacılar tarafından üniversitelerin resmi sitelerinden ulaşılan ilgili web sayfaları ve YÖK tarafından hizmete sunulan https://akademik.yok.gov.tr/AkademikArama/ veri tabanı web sitesinde akademisyenler ile ilgili 2018 yılına gerekli bilgiler elde edilerek titizlikle incelenmiştir. İlgili kaynaklardan, üniversitelerin müzik eğitimi ana bilim dallarında aktif olarak görev yapmakta olan doktora/sanatta yeterlik derecesine sahip öğretim elemanlarının branşları, ulusal ve uluslarası düzeyde yayımlanmış olan kitap, kitap bölümü, makale, kongre ve sempozyum bildirileri, yönettikleri tezler, projeler, aldıkları patent ve ödüller, 2018 yılı verileri ışığında sayısal olarak tespit edilmiştir.

\section{Verilerin Çözümlemesi}

Elde edilen veriler incelenerek, branş ve bilimsel yayın üzerinden sınıflandırılmış; frekans dağılımı ve yüzdelik gibi betimsel istatistiklerden yararlanılarak raporlaştırılmıştır. "Betimsel istatistikler, araştırmacının çok sayıdaki veriyi ve bilgiyi daha az sayıda göstergeye indirgemesine, özetlemesine ve onları anlamlı hale getirmesine yardımcı olur” (Semerci ve diğerleri, 2015, s. 59).

Araştırmada, akademik faaliyetlerin konularına göre sınıflandırılması aşamasında, uzman görüşlerine başvurulmuştur. Herhangi bir sınıflandırmaya tabi tutulmayan konu alanları 'diğer' olarak adlandırılmıştır.

\section{Sınırlılıklar}

Araştırma "doktora ve sanatta yeterlik" derecesine sahip ve 2018-Aralık ayında aktif olarak çalışmakta olan akademisyenler ile yalnızca bilimsel makale, kitap, bildiri, tez, proje çalışmaları ve aldıkları ödül ve patentler ile sınırlandırılmıştır.

\section{BULGULAR}

Tablo 1. Unvanlara Göre Akademisyen Dağılımı

\begin{tabular}{lcc}
\hline Unvan & $f$ & $\%$ \\
\hline Profesör Doktor & 30 & 13,04 \\
Profesör & 19 & 8,26 \\
Doçent Doktor & 53 & 23,04 \\
Doçent & 6 & 2,61 \\
Doktor Öğretim Üyesi & 97 & 42,17 \\
\hline
\end{tabular}




\begin{tabular}{lcc}
\hline Unvan & $f$ & $\%$ \\
\hline Öğretim Görevlisi Doktor & 21 & 9,13 \\
Araştırma Görevlisi Doktor & 4 & 1,74 \\
Profesör Doktor & 30 & 13,04 \\
Toplam & 230 & 100 \\
\hline
\end{tabular}

Tablo 1.'de, Türkiye'deki üniversitelerdeki 30 müzik eğitim anabilim dalında görev yapan öğretim üyesi sayısının 230 olduğu görülmektedir. Akademisyenlerin unvanlara göre dağılımı incelenmiş, akademisyenlerden 30'unun (\%13,04) Profesör Doktor, 19'unun $(\% 8,26)$ Profesör, 53'ünün $(\% 23,04)$ Doçent Doktor, 6'sının $(\% 2,61)$ Doçent, 97'sinin (\%42,17) Doktor Öğretim Üyesi, 21 'inin $(\% 9,13)$ Öğretim Görevlisi Doktor ve 4'ünün $(\% 1,74)$ Araştırma Görevlisi Doktor olarak görev yaptığı belirlenmiştir.

Tablo 2. Akademisyen Sayısının Üniversitelere Göre Dağılımı

\begin{tabular}{|c|c|c|c|c|c|c|c|c|}
\hline Üniversite & Prof. Dr. & Prof. & Doç. Dr. & Doç. & $\begin{array}{l}\text { Dr. Öğr. } \\
\text { Üyesi }\end{array}$ & Öğr. Gör. Dr. & $\begin{array}{l}\text { Arş. Gör. } \\
\text { Dr. }\end{array}$ & Toplam \\
\hline Akdeniz Üniversitesi & & & 1 & & & & & 1 \\
\hline Aksaray Üniversitesi & 1 & & & & 8 & & & 9 \\
\hline $\begin{array}{l}\text { Artvin Çoruh } \\
\text { Üniversitesi }\end{array}$ & & 1 & & & & & & 1 \\
\hline Atatürk Üniversitesi & & & 4 & & & 1 & & 5 \\
\hline $\begin{array}{l}\text { Aydın Adnan } \\
\text { Menderes } \\
\text { Üniversitesi }\end{array}$ & & 1 & & 1 & 5 & & & 7 \\
\hline Balıkesir Üniversitesi & 1 & & 4 & & 3 & 2 & & 10 \\
\hline Bartın Üniversitesi & & & & & 1 & & & 1 \\
\hline $\begin{array}{l}\text { Bolu Abant İzzet } \\
\text { Baysal Üniversitesi }\end{array}$ & 3 & & 1 & & 5 & & & 9 \\
\hline $\begin{array}{l}\text { Burdur Mehmet Akif } \\
\text { Ersoy Üniversitesi }\end{array}$ & 4 & 1 & 3 & & 5 & & & 13 \\
\hline $\begin{array}{l}\text { Bursa Uludağ } \\
\text { Üniversitesi }\end{array}$ & 1 & & 2 & 2 & 4 & 1 & & 10 \\
\hline $\begin{array}{l}\text { Çanakkale On Sekiz } \\
\text { Mart Üniversitesi }\end{array}$ & 1 & & 2 & & 1 & & & 4 \\
\hline $\begin{array}{l}\text { Dokuz Eylül } \\
\text { Üniversitesi }\end{array}$ & 1 & & 4 & & 2 & 4 & & 11 \\
\hline Erzincan Üniversitesi & & & & & 3 & & & 3 \\
\hline Gazi Üniversitesi & 6 & 12 & 8 & & 4 & 3 & 3 & 36 \\
\hline Giresun Üniversitesi & & & 1 & & 3 & & 1 & 5 \\
\hline Harran Üniversitesi & 1 & & & & 5 & & & 6 \\
\hline İnönü Üniversitesi & & 2 & & & 4 & & & 6 \\
\hline $\begin{array}{l}\text { Kastamonu } \\
\text { Üniversitesi }\end{array}$ & & & & & 3 & & & 3 \\
\hline Marmara Üniversitesi & 4 & 1 & 4 & 1 & 3 & 7 & & 20 \\
\hline Mersin Üniversitesi & & & 2 & & & & & 2 \\
\hline $\begin{array}{l}\text { Muğla Sıtkı Koçman } \\
\text { Üniversitesi }\end{array}$ & & & 2 & & 8 & & & 10 \\
\hline $\begin{array}{l}\text { Necmettin Erbakan } \\
\text { Üniversitesi }\end{array}$ & 2 & 1 & 4 & & 5 & & & 12 \\
\hline $\begin{array}{l}\text { Niğde Ömer Halis } \\
\text { Demir Üniversitesi }\end{array}$ & 1 & & 2 & & 5 & & & 8 \\
\hline $\begin{array}{l}\text { On Dokuz Mayıs } \\
\text { Üniversitesi }\end{array}$ & & & 4 & & 2 & 1 & & 7 \\
\hline $\begin{array}{l}\text { Pamukkale } \\
\text { Üniversitesi }\end{array}$ & 1 & & 3 & & 3 & & & 7 \\
\hline $\begin{array}{l}\text { Sivas Cumhuriyet } \\
\text { Üniversitesi }\end{array}$ & 1 & & & & 3 & & & 4 \\
\hline $\begin{array}{l}\text { Tokat Gaziosmanpaşa } \\
\text { Üniversitesi }\end{array}$ & & & & & 6 & & & 6 \\
\hline Trabzon Üniversitesi & 2 & & 2 & & 1 & 2 & & 7 \\
\hline Trakya Üniversitesi & & & & & 2 & & & 2 \\
\hline $\begin{array}{l}\text { Van Yüzüncü Yıl } \\
\text { Üniversitesi }\end{array}$ & & & & 2 & 3 & & & 5 \\
\hline
\end{tabular}


Akademisyenlerin üniversitelere göre dağılımı Tablo 2'de incelenmiş, doktoralı öğretim elemanı sayısının en fazla olduğu üniversitelerin, Gazi Üniversitesi ( $f=36)$, Marmara Üniversitesi $f=20$ ), Burdur Mehmet Akif Ersoy Üniversitesi ( $f=13$ ), Necmettin Erbakan Üniversitesi ( $f=12$ ), Dokuz Eylül Üniversitesi $(f=11)$, Balıkesir Üniversitesi $(f=10)$, Bursa Uludağ Üniversitesi ( $f=10)$ ve Muğla Sıtkı Koçman Üniversitesi ( $f=10)$ olarak belirlenmiştir.

Tablo 3. Branşlara Göre Akademisyen Dağıımı

\begin{tabular}{lcc}
\hline Branş & $f$ & $\%$ \\
\hline Bağlama & 13 & 5,65 \\
Viyolonsel & 14 & 6,09 \\
Flüt & 10 & 4,35 \\
Gitar & 19 & 8,26 \\
Kanun & 1 & 0,43 \\
Keman & 48 & 20,87 \\
Klarnet & 1 & 0,43 \\
Kontrbas & 1 & 0,43 \\
Piyano & 65 & 28,26 \\
Saksafon & 1 & 0,43 \\
Ses Eğitimi & 26 & 11,30 \\
Ut & 1 & 0,43 \\
Viyola & 12 & 5,22 \\
Ulaşlamayan & 18 & 7,83 \\
Toplam & 230 & 100 \\
\hline
\end{tabular}

Tablo 3'te akademisyenlerin branşlarına göre dağılımları incelenmiş, branşların, 65'inin (\%28,26) piyano, 48'inin (\%20,87) keman, $26^{\prime} \operatorname{sının~}(\% 11,60)$ ses eğitimi, 19'unun $(\% 8,26)$ gitar, 14'ünün $(\% 6,09)$ viyolonsel, 13'ünün $(\% 5,65)$ bağlama, 12'sinin $(\% 5,22)$ viyola, $10^{\prime}$ unun $(\% 4,35)$ flüt, $1^{\prime}$ inin $(\% 0,43)$ kanun, $1^{\prime}$ inin $(\% 0,43)$ ut, $1^{\prime}$ inin $(\% 0,43)$ saksafon, $1^{\prime}$ inin $(\% 0,43)$ klarnet ve $1^{\prime}$ inin $(\% 0,43)$ kontrbas olduğu belirlenmiştir. 18 akademisyenin $(\% 7,83)$ ise branşlarına ulaşılamamıştır.

Tablo 4. Akademisyenlerin Bilimsel Yayın Sayıları

\begin{tabular}{lcc}
\hline Yayın Türü & $f$ & $\%$ \\
\hline Kitap ve Kitap Bölümü & 401 & 10,77 \\
Makale & 1734 & 46,56 \\
Bildiri & 1589 & 42,67 \\
Toplam & 3724 & 100 \\
\hline
\end{tabular}

Akademisyenlerin kitap, kitap bölümü, makale ve bildiri yayımlama faaliyetleri Tablo 4'te incelenmiş, yayımlanan kitap ve kitap bölümü sayısının 401 (\%10,77), makale sayısının 1734 (\%46,56), bildiri sayısının ise 1589 (\%42,67) olduğu bulgusuna ulaşılmıştır.

Tablo 5. Akademisyenlerin Bilimsel Yayın Dışı Faaliyet Sayıları

\begin{tabular}{lcc}
\hline Faaliyet Türü & $f$ & $\%$ \\
\hline Proje & 193 & 55,94 \\
Ödül & 151 & 43,77 \\
Patent & 1 & 0,29 \\
Toplam & 345 & 100 \\
\hline
\end{tabular}

Tablo 5'te akademisyenlerin yaptıkları proje, aldıkları ödül ve patent sayıları incelenmiş, akademisyenlerin 193 (\%55,94) proje yaptıkları, $151(\% 43,77)$ ödül ve $1(\% 0,29)$ patent aldıkları belirlenmiştir.

Tablo 6. Akademisyenlerin Makale Sayıları ve Dağılımları

\begin{tabular}{|c|c|c|c|c|c|c|c|c|c|c|}
\hline \multirow[t]{2}{*}{$\begin{array}{l}\text { Makale } \\
(1734)\end{array}$} & \multicolumn{2}{|c|}{ Ulusal } & \multicolumn{2}{|c|}{ Uluslararası } & \multicolumn{2}{|c|}{ Alan Endeksi } & \multicolumn{2}{|c|}{ Diğer İndeksler } & \multicolumn{2}{|c|}{$\begin{array}{c}\text { Indekste } \\
\text { Taranmayanlar }\end{array}$} \\
\hline & $f$ & $\%$ & $f$ & $\%$ & $f$ & $\%$ & $f$ & $\%$ & $f$ & $\%$ \\
\hline & 716 & 41,29 & 1018 & 58,7 & 618 & 35,64 & 868 & 50,06 & 248 & 14,30 \\
\hline
\end{tabular}

Tablo 6'da akademisyenlerin yayımladıkları makaleler incelenmiş, akademisyenlerin 716 (\%41,29) ulusal, 1018 (\%58,7) uluslararası indekslerde makale yayımladıkları belirlenmiştir. Yayımlanmış olan makalelerin 618'inin (\%35,64) alan indekslerinde, $868^{\prime}$ inin $(\% 50,06)$ diğer indekslerde tarandığı, 248'inin (\%14,30) ise herhangi bir indekste taranmadığı belirlenmiştir. 
Tablo 7. Makalelerin Konulara Göre Dağılımı

\begin{tabular}{lcc}
\hline Makale & $f$ & $\%$ \\
\hline Genel Müzik Eğitimi & 294 & 16,96 \\
Çalgı Eğitimi & 324 & 18,69 \\
Piyano Eğitimi & 164 & 9,46 \\
Ses Eğitimi & 84 & 4,84 \\
Armoni Eğitimi & 16 & 0,92 \\
Eğitim Bilimleri & 46 & 2,65 \\
Müzik Felsefesi & 20 & 1,15 \\
Müzik Sosyolojisi & 8 & 0,46 \\
Müzik Psikolojisi & 75 & 4,33 \\
Müzik Tarihi & 10 & 0,58 \\
Müzik Kültürü & 79 & 4,56 \\
Eşlik Eğitimi & 22 & 1,27 \\
Özel Öğretim Yöntemleri & 25 & 1,44 \\
İşitme Eğitimi & 41 & 2,36 \\
Müzik Teknolojileri & 55 & 3,17 \\
Özel Eğitim & 26 & 1,50 \\
Türk Halk Müziği & 47 & 2,71 \\
Türk Sanat Müziği & 14 & 0,81 \\
Eğitim Müziği Besteleme & 9 & 0,52 \\
Diğer & 375 & 21,63 \\
Toplam & 1734 & 100 \\
\hline
\end{tabular}

Tablo 7'de akademisyenlerin yayımladıkları makaleler konu bazında incelenmiş, akademisyenlerin en fazla Çalgı Eğitimi $(\% 18,69)$, Genel Müzik Eğitimi $(\% 16,96)$ ve Piyano Eğitimi $(\% 9,46)$ konularında makale yayımladıkları, yayımlanmış olan makalelerin 375 'inin $(\% 21,63)$ ise müzik eğitimi dışındaki konularda yayımlandığı belirlenmiştir.

Tablo 8. Akademisyenlerin Kitap Sayıları ve Dağılımları

\begin{tabular}{ccccc}
\hline \multirow{2}{*}{ Kitap } & \multicolumn{2}{c}{ Ulusal } & \multicolumn{2}{c}{ Uluslararası } \\
& $f$ & $\%$ & $f$ & $\%$ \\
\hline & 226 & 81,29 & 52 & 18,7 \\
\hline
\end{tabular}

Tablo 8'de akademisyenlerin, 226 (\%81,29) ulusal, 52 (\%18,7) uluslararası olarak nitelendirilen yayınevlerinde kitap yayımladıkları belirlenmiştir.

Tablo 9. Akademisyenlerin Kitap Bölümü Sayıları ve Dağılımları

\begin{tabular}{cccccc}
\hline \multirow{2}{*}{ Kitap Bölümü } & \multicolumn{2}{c}{ Ulusal } & \multicolumn{2}{c}{ Uluslararası } \\
& $f$ & $\%$ & $f$ & $\%$ \\
\hline & 57 & 46,34 & 66 & 53,65 \\
\hline
\end{tabular}

Tablo 9'da akademisyenlerin, 57 (\%46,34) ulusal, 66 (\%53,65) uluslararası olarak nitelendirilen yayınevlerinde kitap bölümü yayımladıkları görülmektedir.

Tablo 10. Kitap ve Kitap Bölümlerinin Konularına Göre Dağılımları

\begin{tabular}{lcc}
\hline Kitap ve Kitap Bölümü & $f$ & $\%$ \\
\hline Genel Müzik Eğitimi & 54 & 13,47 \\
Çalgı Eğitimi & 76 & 18,95 \\
Piyano Eğitimi & 56 & 13,97 \\
Ses Eğitimi & 21 & 5,24 \\
Armoni Eğitimi & 12 & 2,99 \\
Eğitim Bilimleri & 4 & 1,00 \\
Müzik Felsefesi & 3 & 0,75 \\
Müzik Sosyolojisi & 2 & 0,50 \\
Müzik Psikolojisi & 8 & 2,00 \\
Müzik Tarihi & 6 & 1,50 \\
Müzik Kültürü & 24 & 5,99 \\
\hline
\end{tabular}




\begin{tabular}{lcc}
\hline Kitap ve Kitap Bölümü & $f$ & $\%$ \\
\hline Eşlik Eğitimi & 3 & 0,75 \\
Özel Öğretim Yöntemleri & 15 & 3,74 \\
İşitme Eğitimi & 24 & 5,99 \\
Müzik Teknolojileri & 4 & 1,00 \\
Özel Eğitim & 6 & 1,50 \\
Türk Halk Müziği & 9 & 2,24 \\
Türk Sanat Müziği & 6 & 1,50 \\
Eğitim Müziği Besteleme & 12 & 2,99 \\
Diğer & 56 & 13,97 \\
Toplam & 401 & 100 \\
\hline
\end{tabular}

Tablo 10'da akademisyenlerin yayımladıkları kitaplar ve kitap bölümleri konu bazında incelenmiş, akademisyenlerin en fazla Çalgı Eğitimi $(\% 18,95)$, Piyano Eğitimi $(\% 13,97)$ ve Genel Müzik Eğitimi $(\% 13,47)$, konularında kitaplar ve kitap bölümleri yayımladıkları görülmektedir. Yayımlanmış olan kitaplar ve kitap bölümlerinin 56'ının (\%13,97) ise müzik eğitimi dışındaki konularda yayımlandı̆̆ı belirlenmiştir.

Tablo 11. Akademisyenlerin Bildiri Sayıları ve Dağılımları

\begin{tabular}{ccccc}
\hline \multirow{2}{*}{ Bildiri } & \multicolumn{2}{c}{ Ulusal } & \multicolumn{2}{c}{ Uluslararası } \\
& $f$ & $\%$ & $f$ & $\%$ \\
\hline & 482 & 30,33 & 1107 & 69,66 \\
\hline
\end{tabular}

Tablo 11'de akademisyenlerin, $482(\% 30,33)$ ulusal, $1107(\% 69,66)$ uluslararası olarak nitelendirilen bildiri yayımladıkları görülmektedir.

Tablo 12. Bildirilerin Konularına Göre Dağılımları

\begin{tabular}{lcc}
\hline Bildiri & $f$ & $\%$ \\
\hline Genel Müzik Eğitimi & 288 & 18,12 \\
Çalgı Eğitimi & 225 & 14,15 \\
Piyano Eğitimi & 97 & 6,10 \\
Ses Eğitimi & 83 & 5,22 \\
Armoni Ĕgitimi & 31 & 1,95 \\
Eğitim Bilimleri & 22 & 1,38 \\
Müzik Felsefesi & 12 & 0,76 \\
Müzik Sosyolojisi & 23 & 1,45 \\
Müzik Psikolojisi & 37 & 2,33 \\
Müzik Tarihi & 5 & 0,31 \\
Müzik Kültürü & 144 & 9,06 \\
Eşlik Eğitimi & 14 & 0,88 \\
Özel Öğretim Yöntemleri & 23 & 1,45 \\
İşitme Eğitimi & 32 & 2,01 \\
Müzik Teknolojileri & 55 & 3,46 \\
Özel Eğitim & 38 & 2,39 \\
Türk Halk Müziği & 43 & 2,71 \\
Türk Sanat Müziği & 24 & 1,51 \\
Eğitim Müziği Besteleme & 21 & 1,32 \\
Diğer & 372 & 23,41 \\
Toplam & 1589 & 100 \\
\hline
\end{tabular}

Tablo 12'de akademisyenlerin yayımladıkları bildiriler konu bazında incelenmiş, akademisyenlerin en fazla Genel Müzik Eğitimi $(\% 18,12)$, Çalgı Eğitimi $(\% 14,15)$ ve Müzik Kültürü $(\% 9,06)$ konularında bildiriler yayımladıkları belirlenmiştir. Yayımlanmış olan bildirilerin 372 'sinin $(\% 23,41)$ ise müzik eğitimi dışındaki konularda yayımlandığı görülmektedir.

Tablo 13. Akademisyenlerin Yönettikleri Tez Dağılımları

\begin{tabular}{ccccc}
\hline \multirow{2}{*}{ Tez } & \multicolumn{2}{c}{ Ulusal } & \multicolumn{2}{c}{ Uluslararası } \\
& $f$ & $\%$ & $f$ & $\%$ \\
\hline 746 & 77,95 & 211 & 22,04 \\
\hline
\end{tabular}


Tablo 13'te akademisyenlerin yönettikleri tezler incelenmiş ve 746 (\%77,95) yüksek lisans, 211 (\%22,04) doktora tezi yönettikleri belirlenmiştir.

\section{TARTIŞMA}

Müzik eğitimi lisans programı, Türkiye'nin tamamında tüm üniversitelerin eğitim fakültelerinde ortak olarak yürütülen programlardır. Bu program içerisinde, bilimsel araştırmaya yönelik hem eğitim dersi olarak hem de alan içi diğer derslerin çoğunda bilimsel araştırmayı destekleyen öğretici ve geliştirici çalışmalar yapılmaktadır. Lisans eğitimi sürecini başarılı bir şekilde tamamlayan öğrenciler, lisansüstü programlarla, "bilim uzmanı" ve "bilim doktoru" unvanı almaya hak kazanmaktadır. Müzik eğitimine yönelik lisansüstü eğitim programı sayılarının, diğer alanlardaki lisansüstü programlara göre sayıca daha az olduğu ve yeni yeni artmakta olduğu söylenebilir. Bu artışla birlikte lisansüstü öğrenci sayısının ve niteliğinin artması beklenen ve arzu edilen bir durumdur. Ancak bu durum lisans eğitimi öncesini de çok yakından ilgilendirmektedir. Çetinkaya (2006), bilim ve eğitimin birlikte hareket etmesi gerekliliğini; okul öncesi evreden başlayan, araştırıcı düşünceyi geliştirmeye yönelik, bilimsel yöntemi günlük yaşama katabilen, yaratıcı ve sorgulayıcı zihinler inşa edilmesi zorunluluğunu vurgulamış ve bunun sağlıklı eğitim politikaları ile sağlanabileceğini belirtmiştir (s. 17).

Sağlıklı eğitim politikalarının geliştirilmesi ile birlikte, bilimsel araştırma yöntem ve teknikleri ile yapılacak olan araştırmaların ürünleri, sağlam bir zemin üzerine oturacak ve hangi bilim alanı olursa olsun, literatürde kendine sağlam bir yer bulacaktır. Bunun için en temel kazanımların edinilmesinde ve daha karmaşık yapıların çözümlenip yorumlanabilmesinde, eğitimin, bilimin ve bilimsel araştırmanın önemi kendini ön plana çıkarmaktadır.

"Yetiştirilecek olan bilim insanının lisansüstü eğitimle (yüksek lisans ve doktora) yetiştirilmesinde 'araştırma teknik yeterlikleri' ve "bilimsel tutum ve davranışlarının kazandırılması, alanında yapacağı araştırmaların doğru yapılabilmesi açısından oldukça önemlidir. Eğer yetiştirilecek bilim insanına lisansüstü eğitimle yeterli 'araştırma eğitimi' verilemezse hem yapılan araştırmalar yanlışlarla dolu olacaktır, hem de araştırma için harcanan zaman, emek ve para boşa gidecektir” (Erdem, 2012, s. 166). "Bilimci kendi alanındaki çalışmalara hakim olmalı, bunun için de sürekli kendi alan yazınını takip etmelidir. Özellikle hakemli dergilerde yayımlanmış olan makaleleri taramak, problem bulmak ve bulduğumuz problemin yenilik getirip getirmediği ve önemli olup olmadığını görebilmek açısından çok yararlı ve hatta zorunludur" (Erkuş, 2017, s. 74).

Erdoğan (2006) 'Bilimsel Makale Etiği: Eleştirel Gözlemler’ adlı çalışmasında şu başlıklara dikkat çekmiştir;

- Çok söz ve dipnota karşılık az fikir

- Alanyazını ihmal etme veya görmezlikten gelme

- Atıf vermede sorun

- Eleştiriye açık olmama ve eleştiri yokluğu

- Hatır için yazı yayımlama

- $\quad$ Ideoloji etmeni (faktörü)

- Hakemlik kurumu

- Yabancı dilde yayım sorunu

Tüm bunlar ışığında müzik eğitimi alanında yapılacak olan bilimsel çalışmaların, dünyada yapılan müzik ve müzik eğitimi çalışmalarına entegre olması, alana ait sorunları doğru ve yerinde tespit edebilmesi, literatürü iyi tanıması ve değerlendirmesi, yansız ve gerçekçi yaklaşımlarla, doğru ve yerinde bilimsel yöntemler kullanarak müzik eğitimi alanına katkı sağlaması, müzik eğitimi araştırmaları adına beklenen bir durumdur.

\section{SONUÇ VE ÖNERILER}

Bu araştırmada Türkiye'de müzik eğitimi anabilim dallarında görev yapan doktora/sanatta yeterlik yapmış olan öğretim elemanlarının alan içi çalışmalarına yönelik bir inceleme yapılmıştır.

Türkiye' deki üniversitelerdeki 30 müzik eğitim anabilim dalında görev yapan doktoralı öğretim elemanı sayısının YÖK Akademik veri tabanı ve ilgili üniversitelerin web sitelerinden elde edilen verilerle 230 olduğu tespit edilmiştir. Akademisyenlerin unvanlara göre dağılımı incelenmiş, akademisyenlerden 30'unun (\%13,04) Profesör Doktor, 19'unun (\%8,26) Profesör, 53'ünün (\%23,04) Doçent Doktor, 6'sının $(\% 2,61)$ Doçent, 97'sinin $(\% 42,17)$ Doktor Öğretim Üyesi, 21'inin $(\% 9,13)$ Öğretim Görevlisi Doktor ve 4'ünün $(\% 1,74)$ Araştırma Görevlisi Doktor olarak görev yaptığı tespit edilmiştir. Elde edilen verilere göre profesör ve doçent unvanı alan akademisyen sayısının doktor ve doktor öğretim üyesi sayısına göre az olduğu, öte yandan profesör ve doçent unvanı alma potansiyeline sahip akademisyen sayısının fazla olduğu söylenebilir.

Akademisyenlerin üniversitelere göre dağılımı incelenmiş, doktoralı öğretim elemanı sayısının en fazla olduğu üniversiteler; Gazi Üniversitesi $(f=36)$, Marmara Üniversitesi $f=20)$, Burdur Mehmet Akif Ersoy Üniversitesi ( $f=13)$, Necmettin Erbakan Üniversitesi $(f=12)$, Dokuz Eylül Üniversitesi $(f=11)$, Balıkesir Üniversitesi $(f=10)$, Bursa Uludağ Üniversitesi $(f=10)$ ve Muğla Sıtkı Koçman Üniversitesi ( $f=10$ ) olarak belirlenmiştir.

Akademisyenlerin branşlarına göre dağılımları incelenmiş, branşların, 65'inin (\%28,26) piyano, 48'inin (\%20,87) keman, 26'sının $(\% 11,60)$ ses eğitimi, $19^{\prime}$ unun $(\% 8,26)$ gitar, $14^{\prime}$ ünün $(\% 6,09)$ viyolonsel, $13^{\prime}$ ünün $(\% 5,65)$ bağlama, $12^{\prime}$ sinin $(\% 5,22)$ viyola, 10'unun $(\% 4,35)$ flüt, $1^{\prime}$ inin $(\% 0,43)$ kanun, $1^{\prime}$ inin $(\% 0,43)$ ut, $1^{\prime}$ inin $(\% 0,43)$ saksafon, $1^{\prime}$ inin $(\% 0,43)$ klarnet ve 1 'inin $(\% 0,43)$ kontrbas 
olduğu belirlenmiştir. 18 akademisyenin $(\% 7,83)$ ise branşlarına ulaşılamamıştır. Elde edilen verilere göre branşı piyano ve keman olan akademisyen sayısının fazla olduğu, bunun piyano dersinin zorunlu olmasına ve müzik eğitimi anabilim dallarında yürütülen orkestra dersinde keman öğrencisinin oldukça fazla olmasına bağlı olduğu söylenebilir.

Akademisyenlerin kitap, kitap bölümü, makale ve bildiri yayımlama faaliyetleri incelenmiş, yayımlanan kitap ve kitap bölümü sayısının 401 (\%10,77), makale sayısının 1734 (\%46,56), bildiri sayısının ise $1589(\% 42,67)$ olduğu tespit edilmiştir. Elde edilen verilere göre akademisyenlerin makale ve bildiri sayılarının kitap ve kitap bölümü sayısına göre daha fazla olduğu görülmektedir. Yaptıkları proje, aldıkları ödül ve patent sayıları incelenmiş, $193(\% 55,94)$ proje yaptıkları, $151(\% 43,77)$ ödül ve 1 (\%0,29) patent aldıkları tespit edilmiştir. Patent ile ilgili çalışmalara yeterli düzeyde ağırık verilmediği görülmektedir. Yayımlanan makaleler incelendiğinde ise, 716 (\%41,29) ulusal, $1018(\% 58,7)$ uluslararası indekslerde makale yayımlandığı sonucuna ulaşılmıştır. Yayımlanmış olan makalelerin 618'inin $(\% 35,64)$ alan indekslerinde, 868'inin $(\% 50,06)$ diğer indekslerde tarandığı, 248'inin $(\% 14,30)$ ise herhangi bir indekste taranmadığı tespit edilmiştir. Buradan hareketle, akademisyenlerin çoğunluğunun uluslararası taranan dergilerde makaleler yayımladıkları söylenebilir. Ayrıca yayımlanmış olan makalelerin büyük çoğunluğunun alan dışı indekslerde tarandığı ve indekste taranmayan makaleler ile birlikte ele alındığında alan indeksinde yayımlanan makale sayısının diğerlerine göre düşük olduğu sonucu elde edilmiştir.

Akademisyenlerin yayımladıkları makaleler konu bazında incelendiğinde, en fazla Çalgı Eğitimi (\%18,69), Genel Müzik Eğitimi $(\% 16,96)$ ve Piyano Eğitimi $(\% 9,46)$ konularında makale yayımladıkları tespit edilmiştir. Yayımlanmış olan makalelerin 375 'inin ise müzik eğitimi dışındaki konularda yayımlandığı belirlenmiştir.

Akademisyenlerin, $226(\% 81,29)$ ulusal, 52 (\%18,7) uluslararası olarak nitelendirilen yayınevlerinde kitap yayımladıkları tespit edilmiş ve ulusal yayın sayısının, uluslararası yayın sayısına göre fazla olduğu görülmektedir. Kitap bölümü sayısı açısından ele alındığında ise, $57(\% 46,34)$ ulusal, $66(\% 53,65)$ uluslararası olarak nitelendirilen yayınevlerinde kitap bölümü yayımladıkları tespit edilmiş ve uluslararası yayın sayısının, ulusal yayın sayısına göre fazla olduğu sonucuna ulaşılmıştır. Yayımladıkları kitaplar ve kitap bölümleri konu bazında incelendiğinde, en fazla Çalgı Eğitimi (\%18,95), Piyano Eğitimi $(\% 13,97)$ ve Genel Müzik Eğitimi (\%13,47), konularında kitaplar ve kitap bölümleri yayımladıkları tespit edilmiştir. Yayımlanmış olan kitaplar ve kitap bölümlerinin $56^{\prime} ı n ı n$ $(\% 13,97)$ ise müzik eğitimi dışındaki konularda yayımlandığı belirlenmiş, akademisyenlerin büyük çoğunluğunun müzik eğitimi konularını ele alan kitap ve kitap bölümü yayımladıkları bununla birlikte müzik eğitimi dışındaki müzikle bağlantılı konularda kitap ve kitap bölümü yayımladıkları da görülmektedir.

Akademisyenlerin katıldıkları sempozyumlarda, 482 (\%30,33) ulusal, $1107(\% 69,66)$ uluslararası olarak nitelendirilen bildiri yayımladıkları belirlenmiş, uluslararası sempozyumlara daha fazla katılım sağladıkları tespit edilmiştir. Yayımladıkları bildiriler konu bazında incelendiğinde, en fazla Genel Müzik Eğitimi $(\% 18,12)$, Çalgı Eğitimi $(\% 14,15)$ ve Müzik Kültürü $(\% 9,06)$ konularında bildiriler yayımladıkları belirlenmiştir. Yayımlanmış olan bildirilerin 372 'sinin $(\% 23,41)$ ise müzik eğitimi dışındaki konularda yayımlandığı belirlenmiştir. Elde edilen verilere göre akademisyenlerin çoğunluğunun müzik eğitimini ele alan bildiriler yayımladıkları, müzik eğitimi konularının dışında da yayımladıkları bildiri sayısının fazla olduğu tespit edilmiştir.

Akademisyenlerin yönettikleri tezler incelendiğinde 746 (\%77,95) yüksek lisans, 211 (\%22,04) doktora tezi yönettikleri belirlenmiştir. Bu verilere göre akademisyenlerin çok sayıda yüksek lisans tezi yönettiği, doktora programı sayısının az olması ve program kriterlerinin ağır olması sebebi ile yönetilen doktora tezi sayısının az olduğu söylenebilir.

Türkiye'de müzik eğitimi anabilim dallarında yapılan akademik çalışmalarının tamamının 4681 adet olduğu saptanmıştır. Mevcut durum göz önüne alındığında, ulusal ve uluslararası çalışmaların sayısal olarak arttırılması ve durumun iyileştirilmesine yönelik çalışmalar yapılması önem arz etmektedir. Diğer yandan, bilimsel çalışmaların nicelik ve bununla beraber niteliğinin arttırılması için mevcut akademisyen sayısının arttırılması, lisansüstü programların daha cazip hale getirilerek yeni akademisyenler yetiştirilmesi ve akademisyenlerin bilimsel çalışmaya teşvik edilmesi müzik eğitimi alanı açısından gerekli bir durumdur.

\section{KAYNAKÇA}

Alparslan, A. (2014). Öğretim elemanlarının işlerinden tatmin, üniversitelerinden memnun ve gönüllü olmalarındaki öncüller: Mehmet Akif Ersoy Üniversitesi'nde bir araştırma. Mehmet Akif Ersoy Üniversitesi Sosyal Bilimler Enstitüsü Dergisi, 6(11), 82-101

Arıkan H. ve Demir, G.Y. (2009) Akademisyenlik ve etik: uygulamalar üzerine toplumsal bir değerlendirme. VI. Ulusal Sosyoloji Kongresi Toplumsal Dönüşümler ve Sosyolojik Yaklaşımlar. (202-237). Aydın.

Boyer, E. L. (1990). Scholarship reconsidered: priorities of the professoriate. USA, New Jersey: Princeton University Press.

Büyüköztürk, Ş., Kılıç Çakmak, E., Akgün, Ö.E., Karadeniz, Ş. ve Demirel, F. (2015). Bilimsel araştırma yöntemleri. Ankara: Pegem Akademi.

Çetinkaya, H. (2006). Evrim, bilim ve eğitim üzerine. Ege Eğitim Dergisi. 7 (1), 1-21.

Deem, R. and Lucas, L. (2007). Research and teaching cultures in two contrasting UK policy contexts: academic life in education departments in five english and Scottish universities. Higher Education, 54(1), 115-133.

Doğan, M. (2013). Bilim ve teknoloji tarihi: Sümerlilerden günümüze bilim ve teknoloji, Cumhuriyet Türkiye'sinde bilim ve teknoloji. Ankara: Anı Yayıncilık.

Düztepe, Ş. (2004). Araştırmalarda bilimsel yöntemin kullanılması ve araştırmanın temel aşamaları. Journal of Aeronautics and Space Technologies, 1(3), 49-53.

Ecevit, M. C. (2006). Bilimsel pratikte etik sorunların toplumsal birkaç yönü. E. Karakütük (Ed.), Sosyal Bilimlerde Süreli Yayıncılık-1. Ulusal Kurultay Bildirileri. (s. 81-87) içinde. Ankara. 
Ekiz, D. (2015) Bilimsel araştırma yöntemleri yaklaşım, yöntem ve teknikler. Ankara: Anı Yayıncılık.

Erdem, A. R. (2012). Bilim insanı yetiştirmede araştırma eğitimi. Yükseköğretim ve Bilim Dergisi, 2(3), 166-175.

Erdoğan, M. (2006). Bilimsel makale yazma etiği: eleştirel gözlemler. K. Karakütük (Ed.), Sosyal Bilimlerde Süreli Yayıncllık-1. Ulusal Kurultay Bildirileri. (s. 95-97) içinde. Ankara.

Erkuş, A. (2011). Davranış bilimleri için bilimsel araştırma süreci. Ankara: Seçkin Yayıncılık.

Erkuş, A., Sünbül, Ö., Sünbül, Ö. S., Yormaz, S. ve Aşiret, S. (2017). Psikolojide ölçme ve ölçek geliştirme 2: ölçme araçlarının psikometrik nitelikleri ve ölçme kuramları. Ankara: Pegem Akademi.

Günay, D. (2011). Türk yükseköğretiminin yeniden yapılandırılması bağlamında sorunlar, eğilimler, ilkeler ve öneriler-ı. Yükseköğretim ve Bilim Dergisi, 1(3), 113-121.

Kaptan, S. (1998). Bilimsel araştırma ve istatistik teknikleri (11. Bs). Ankara: Tek Işık Web Ofset.

Karasar, N. (2011). Bilimsel araştırma yöntemleri. Ankara: Nobel Yayın Dağıtım.

Odabaşı, F., Fırat, M., İzmirli, S., Çankaya, S. ve Mısırlı, A. (2010). Küreselleşen dünyada akademisyen olmak. Anadolu Üniversitesi Sosyal Bilimler Dergisi, 10(3), 127-142.

Okur, H. M. (2007). Marka yükseköğretim hizmetlerinin pazarlanmasında marka değeri oluşturma ve geliştirme stratejileri: Ankara ilinde örnek bir çalışma. (Yüksek lisans tezi). YÖK tez veri tabanından erişildi (Tez No: 211839).

Ortaş, ì. (2004). Öğretim üyesi ya da bilim insanı kimdir?. Pivolka, 3, 11-16.

Özer, Y. E. (2011). Girişimci üniversite modeli ve Türkiye. Uludağ Üniversitesi Iktisadi ve Idari Bilimler Fakültesi Dergisi, 30(2), 85-100.

Parasız, G. (2009). Keman öğretiminde kullanılmakta olan çağdaş Türk müziği eserlerinin seslendirilmesine yönelik olarak oluşturulan hazırlayıcı alıştırmaların işgörüsellik ve etkililik yönünden incelenmesi. (Doktora tezi). YÖK tez veri tabanından erişildi (Tez No: 239242).

Sönmez, V. ve Alacapınar, F. G. (2011). Örneklendirilmiş bilimsel araştırma yöntemleri. Ankara: Anı Yayınclık.

Sönmez, V. ve Alacapınar, F. G. (2016). Örneklendirilmiş bilimsel araştırma yöntemleri. Ankara: Anı Yayınclık.

Semerci Ç., Gündoğdu K., Sezgin F., Demircioğlu G,. Köse, E., Yılmaz, A., Çepni, S., Bayrakçeken, S. ve Yücel C. (2015). Ölçme ve değerlendirme. Ankara: Pegem Akademi.

Şahin, M. ve Duman, R. (2008). Cumhuriyetin yapılanma sürecinde müzik eğitimi. Çağdaş Türkiye Tarihi Araştırmaları Dergisi, 7(16), $259-272$.

Tomakin, E. (2009). Bilimsel çalışmalarda yaklaşım, yöntem ve teknik problemi: alternatif bir yorum. Ankara Üniversitesi Eğitim Bilimleri Fakültesi Dergisi, 42(1), 105-128.

Topdemir, H. G. ve Unat, Y. (2013). Bilim tarihi. Ankara: Pegem Akademi.

Uçan, A. (2005). Insan ve müzik, insan ve sanat eğitimi, temel kavramlar-ilkeler-yaklaşımlar, Türkiye'deki durum. Ankara: Evrensel Müzikevi.

Ültay, E. ve Ültay, N. (2018). Akademik teşvik ödeneğinin bilimsel faaliyetlere etkisi hakkındaki akademisyen görüşleri. Yükseköğretim ve Bilim Dergisi, 8(1), 162-171.

Verburgh, A., Elen, J. and Lindblom-Ylänne, S. (2007). Investigating the myth of the relationship between teaching and research in higher education: a review of empirical research. Studies in Philosophy and Education, 26(5), 449-465.

Yaşar, Ş. (1998). Çağdaş yaşam çağdaş insan. Can. G. (Ed.). Çağdaş Bilim Anlayışı (s. 154- 162). Eskişehir: Anadolu Üniversitesi Açıköğretim Fakültesi Yayınları.

Yükseköğretim Akademik Arama (2018). Erişim adresi: https://akademik.yok.gov.tr/AkademikArama/ 